\title{
CODE-SWITCHING NA COMUNIDADE KAINGANG DA TERRA INDÍGENA GUARITA
}

Celina Eliane Frizzo ${ }^{1}$

Marcelo Jacó Krug² Cristiane Horst $^{3}$

Resumo: No presente artigo, tratamos do contato linguístico entre a língua Kaingang e a língua portuguesa na Terra Indígena Guarita. Buscamos compreender a questão do bilinguismo, trazendo sua definição a partir de uma revisão bibliográfica baseada em Mackey (1972); Poplack (1980); Appel \& Muysken (1987); Hamers \& Blanc (2000) e Romaine $(1995,2013)$. A partir disso, trazemos a nossa compreensão de Code-Switching, uma habilidade do falante bilíngue, que diferenciamos e relacionamos com o empréstimo. Definimos o Code-Switching como sendo uma forma de utilizar o empréstimo, que não exige dos interlocutores um amplo domínio de ambas as línguas. $\mathrm{Na}$ análise realizada, percebemos a ocorrência do Switching intersentencial, e o Switching intrasentencial, Poplack (1980).

Palavras-chave: Contato Linguístico, Bilinguismo, Code-Switching, Língua Kaingang.

\section{CODE-SWITCHING IN A KAINGANG COMMUNITY AT GUARITA INDIGENOUS LAND}

\begin{abstract}
In this article, we address the linguistic contact between the Kaingang language and the Portuguese language in the Guarita Indigenous Territory. We seek to understand the matter of bilingualism, whose definition is based on a literature review of Mackey (1972); Poplack (1980); Appel \& Muysken (1987); Hamers \& Blanc (2000) and Romaine (1995, 2013). Based on that, we understand Code-Switching as a skill of the bilingual speaker, which we differentiate and relate to the borrowing. We defined CodeSwitching as a way to use the loanwords, which does not require interlocutors to have a vast knowledge of both languages. In the analysis carried out, we noticed the occurrence of inter and intrasentential sentential switching, Poplack (1980).
\end{abstract}

Keywords: Languages in Contact. Bilingualism. Code-Switching. Kaingang Language.

1 Mestre em Estudos Linguísticos (UFFS), e-mail: celinafrizzo@hotmail.com

2 Doutorado em Filologia Românica pelo Christian-Albrechts-Universität Zu Kiel, Alemanha, e-mail: marcelokrug.mk@gmail.com

3 Doutora em Letras/Filologia Românica pela Christian-Albrechts-Universität zu Kiel (Alemanha). e-mail cristianehorst@yahoo.de 


\section{O contato linguístico Kaingang - Português: contextualização}

O contato linguístico que ocorre entre comunidades que usam diferentes variedades/línguas nos apresenta um campo repleto de estudos e reflexões das mais variadas esferas. No presente trabalho, apresentamos exemplos de Code-Switching encontrados em uma situação de contato linguístico - Kaingang - Português na Terra Indígena Guarita (doravante TIG). Nossos dados são oriundos de pesquisa de campo com gravação de conversas, a partir da aplicação do questionário linguístico e metalinguístico adaptados do Atlas das Línguas em Contato na Fronteira - ALCF (Krug, 2013), conversa livre e anotações em caderno de campo ${ }^{4}$. A partir desses dados, foi possível inferir a intensidade desse contato, observando as diversas formas como ele ocorre. Dentre elas, temos desde o indígena que vai até a cidade vender ou comprar produtos e alimentos, até o seu contato direto com profissionais da saúde, educação, agricultura e meio ambiente, entre outros, que atuam dentro da Terra Indígena.

Nessa relação de contato entre variedades linguísticas distintas, na qual uma é a oficial do país e a outra é a oficial na comunidade, o indígena é levado, por uma questão de sobrevivência e de defesa de sua cultura, seus direitos e interesses, a aprender a variedade da língua portuguesa oral e escrita. O foco de nosso estudo está na relação entre a língua Kaingang e a língua portuguesa, mais especificamente em como elas convivem entre si e investigar de que forma ocorre o Code-Switching, processo decorrente do bilinguismo.

O grupo Kaingang em questão vive na TIG, localizada no noroeste do Rio Grande do Sul, próximo da divisa entre Brasil e Argentina. Segundo dados do Instituto Brasileiro de Geografia e Estatística-IBGE (2010), são aproximadamente 6.001 Kaingang que vivem neste território, o que o caracteriza como a maior terra indígena em número de habitantes do estado. Atualmente, conta com uma extensão de 23.406 hectares, demarcados oficialmente em 1918 (WISNIEWSKI, 2011).

Figura 1 - Localização da TIG

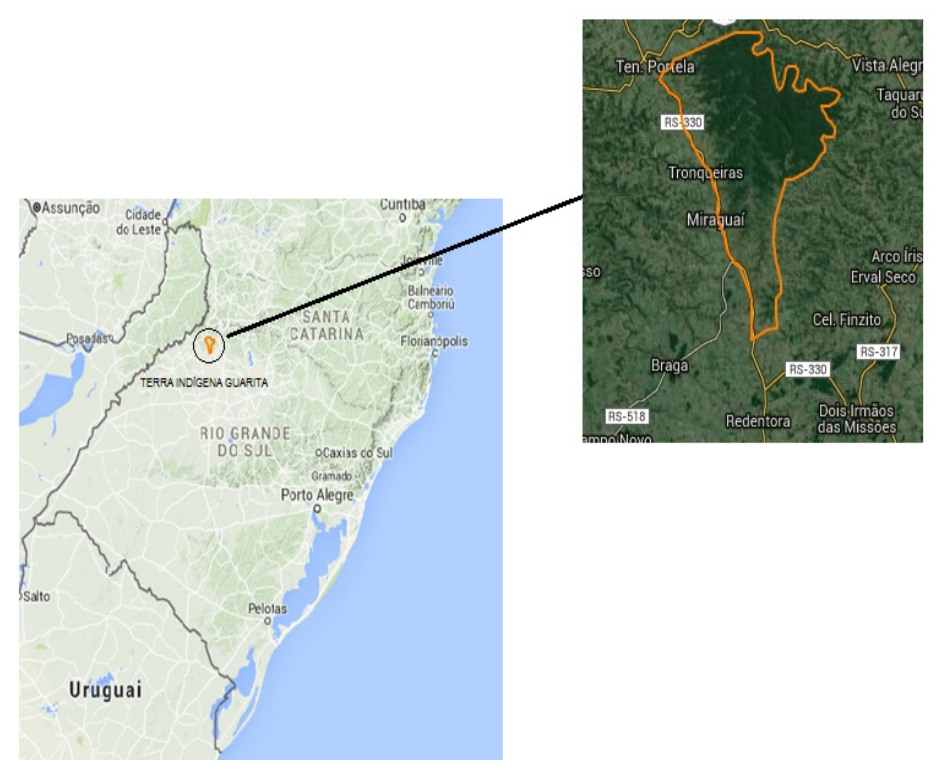

Fonte: FRIZZO, 2017, p. 20

4 O presente trabalho teve a aprovação do CEP sob CAAE XXXXXXXXX 
Atualmente, a TIG está organizada em pequenas comunidades, o que, segundo D’Angelis \& Veiga (2003), se deve ao estabelecido pelos órgãos indigenistas oficiais (até 1967 o Serviço de Proteção aos Índios - SPI, e depois disso à Fundação Nacional do Índio - FUNAI). "A Funai consagrou, nos anos 70, o enfileiramento de tais casas padrão ao longo das estradas de acesso às áreas, muitas das quais são hoje, movimentadas rodovias com asfalto" (D'ANGELIZ \& VEIGA, 2003, p. 04), sendo esta a realidade atual da TIG, onde muitas moradas se situam na beira da RS 330, havendo comunidades próximas dos centros urbanos dos municípios de Tenente Portela, Redentora e Miraguaí, onde se dirigem para realizar a compra de condimentos, roupas, medicamentos entre outros.

Além do contato entre indígenas e não indígenas gerado pela localização das comunidades, outro fator que corrobora para o contato entre os dois grupos é o trabalho de instituições voltadas para assistir e atender a comunidade. Podemos citar as principais, como a SESAI - Secretaria Especial de Saúde Indígena, que é responsável por coordenar a Política Nacional de Atenção à Saúde dos Povos Indígenas e todo o processo de gestão do Subsistema de Atenção à Saúde Indígena (SasiSUS), no âmbito do Sistema Único de Saúde $(\mathrm{SUS})^{5}$, a FUNAI, que monitora e fiscaliza as terras indígenas, além de assegurar o acesso aos direitos sociais e de cidadania aos povos indígenas, o COMIN - Conselho de Missão entre Povos Indígenas, cujo objetivo é proporcionar apoio político e institucional às pessoas da igreja que estão junto às comunidades indígenas, através da IECLB - Igreja Evangélica de Confissão Luterana no Brasil e, por fim, a EMATER - Empresa de Assistência Técnica e Extensão Rural, que realiza atividades individuais e coletivas, compreendendo

5 Informações retiradas do site: http://www.saude.gov.br/ sesai. Acessado no dia 17/07/2020. o planejamento, a execução, a avaliação e o controle social, com vistas à promoção da segurança alimentar e nutricional, incremento de renda e a inclusão produtiva e social das famílias envolvidas no projeto.

Outra instituição que merece ser descrita são as igrejas evangélicas e pentecostais. Atualmente, segundo Ferrari (2012), a Igreja Assembleia de Deus é a que possui mais adeptos na comunidade indígena, seguida da Igreja Só o Senhor é Deus. Um número menor de famílias pertence à Igreja Católica e IECLB. Ainda segundo o autor, o pentecostalismo (representado pela Igreja Assembleia de Deus) agrega características do imaginário religiosocultural Kaingang. Assim, as igrejas da sociedade do fóg $g^{6}$ adentram o espaço indígena e são uma das causas das mudanças culturais indígenas, bem como a escola (GASPARETO, 2006).

Quanto às instituições de ensino na TIG, há 13 escolas estaduais no total, sendo que uma delas possui ensino médio e as demais possuem ensino fundamental. $O$ corpo docente das escolas indígenas, em sua maioria, é formado por professores não-indígenas. Mesmo havendo a falta de professores habilitados no ensino da língua Kaingang, busca-se trabalhar o idioma indígena do $1^{\circ}$ ao $4^{\circ}$ ano do ensino fundamental. A partir dos anos seguintes, trabalha-se, apenas, com a língua portuguesa. No entanto, cada escola tem autonomia de gerenciar a forma como irá desenvolver seu trabalho mediante ao quadro de profissionais que possui. De modo geral, o público das escolas indígenas são os moradores da TIG, ou seja, os indígenas. Contudo, há casos de alunos indígenas que frequentam as escolas na cidade, as quais não trabalham a língua Kaingang, apenas o português em todas as etapas de ensino.

$\mathrm{Na}$ maioria das comunidades (também chamados de setores) da TIG, há pavilhões

6 O vocábulo fóg é um termo Kaingang que se refere ao não indígena. 
comunitários, que servem para a realização de festas, casamentos, cultos religiosos, reuniões entre as lideranças indígenas ou eventos realizados por entidades como EMATER, COMIN, SESAI e FUNAI, entre outros. É o local de encontro do setor entre indígenas e entre indígenas e fóg. O que chama a atenção é que em seu entorno acabam se instalando outros estabelecimentos, como escolas, unidades de saúde e igrejas, tornando-se o centro da comunidade.

Essa característica na forma de organização espacial pode estar vinculada às ações realizadas pelo SPI e FUNAI ao longo de seus trabalhos, pois ao organizar a população indígena em forma de vilas mostrava para a sociedade não indígena que a inserção dos nativos no "mundo dos brancos" estava acontecendo. Além disso, esse arranjo facilitava a construção em grande escala e, mais tarde, contribuía para a implementação de redes de água. Normalmente, as comunidades indígenas constroem suas casas próximas de suas roças e de seus familiares, tendo o grande chefe da família como orientador. Segundo D’Angeliz \&Veiga (2003)

\begin{abstract}
"No passado, os grupos costumavam viver em grandes casas, uma espécie de cabana coberta por folhas de palmeiras, sem repartição alguma, tendo apenas uma abertura estreita para entrada e saída. De pouca durabilidade, quando se encontravam em estado precário, eram queimadas e uma nova era erguida" (D’ANGELIZ \& VEIGA, 2003)
\end{abstract}

Outra questão que gostaríamos de trazer para reflexão é o contato oriundo dos arrendamentos de áreas agrícolas. Segundo Gaspareto (2006), além da exploração da madeira, a TIG sofreu com o arrendamento de suas terras por parte dos fóg. Esse arrendamento ocorreu após o SPI ter assumido o comando das terras. Na década de 70 e 80, do total da área produtiva, 80\% das terras estavam sob poder dos arrendatários e, mesmo sendo proibido em 1973, o arrendamento continuou. Muitos conflitos entre indígenas e arrendatários se travaram até que a situação fora resolvida e os colonos se retirassem da TIG (MATTE, 2004 apud GASPARE'TO, 2006). Atualmente constatou-se que, apesar de proibido, ainda existem pequenas áreas arrendadas para não indígenas na TIG, corroborando, dessa forma, com o contato entre indígenas e fóg.

Em suma, com a descrição da comunidade de pesquisa, podemos ter uma percepção de como ocorre o contato linguístico entre Kaingang e fóg da TIG. Além disso, vale ressaltar que, a partir dessas informações da comunidade de pesquisa, somados ao conceito de Bilinguismo, como veremos a seguir, compreenderemos melhor a manifestação de CodeSwitching lá encontrada.

\section{Bilinguismo e Code-Switching na Terra Indígena Guarita}

O Bilinguismo, muitas vezes, é visto pelo senso comum como sendo o domínio igual e equilibrado de duas línguas. Em linhas teóricas, encontramos várias definições para o termo Bilinguismo. Inicialmente Bloomfield (1933 apud ROMAINE, 1995), define o bilinguismo como o controle nativo de duas línguas.

Mas os estudos a respeito do bilinguismo vão se redefinindo ao longo do século XX. Macnamara, em 1969 (apud APPEL \& MUYSKEN, 1987), por sua vez, propõe que um indivíduo pode ser chamado de bilíngue se ele possuir alguma habilidade (falar, ouvir, escrever e ler) em segunda língua, adicionado a suas habilidades em primeira língua. Nesta mesma perspectiva, Grosjean (2010, p. 04) entende que "bilíngues são aqueles que usam duas ou mais línguas (ou dialetos) em sua vida diária”. Assim, vários são os conceitos e de diferentes proporções, o que nos mostra que definir bilinguismo é algo relativo como afirma Mackey (1979, p. 555) “o bilinguismo é um fenômeno relativo, um comportamento de práticas linguísticas, mutuamente modificadas, variando em 
grau, função, alternância e interferência” não sendo possível descrevê-lo dentro do campo da linguística apenas.

Para Appel \& Muysken (1987, p. 02), "quase todas as sociedades são bilíngues", ou seja, na maioria das sociedades ocorre o contato entre línguas, compreendido como "o uso de dois ou mais códigos nas relações interpessoais e intergrupais, bem como o estado psicológico de um indivíduo que usa mais de uma língua" (HAMERS \& BLANC, 2000, p. 06).

O que determina o uso de uma ou outra dessas línguas, num contexto bilíngue, deve-se em partes, às crenças e atitudes linguísticas do falante perante às línguas. Atitudes relacionadas à língua vêm sendo investigadas em pesquisas sociolinguísticas para “analisar fenômenos em relação ao comportamento linguístico, seja este comportamento vinculado a variantes específicas de uma variedade ou às variedades em si..." (KAUFMANN, 2011, p. 122). Para Aguilera (2008),

... a atitude linguística de um indivíduo é o resultado da soma de suas crenças, conhecimentos, afetos e tendências a comportar-se de uma forma determinada diante de uma língua ou de uma situação sociolinguística. (AGUILERA, 2008, p.106).

Dessa forma, as crenças e atitudes também estão relacionadas ao uso de uma ou outra língua, ou seja, um indivíduo vai fazer uso de determinada língua, por exemplo, uma língua de menor prestígio, quando essa convir; caso contrário, estima-se que sempre utilizará a variedade de maior prestígio. Isso depende muito do interlocutor, pois se ambos dominam as variedades em questão, pode ocorrer a mudança ou a troca linguística entre as duas variedades, ocorrendo o que é denominado pela literatura de Code-Switching ${ }^{7}$. Tratar desse tema se torna um ato cauteloso, uma vez que existem lacunas, questões conflituosas e até divergentes, inclusive, na definição da nomenclatura utilizada.

7 Veja (APPEL \& MUYSKEN, 2006); (HAMERS \& BLANC, 2000); (MUYSKEN, 2011)
Assim, para Gumperz (1982, p. 59), o CodeSwitching pode ser definido como "a justaposição dentro da fala de passagens do discurso pertencentes a dois sistemas gramaticais diferentes ou subsistemas". O Code-Switching foi classificado em três tipos por Poplack (1980); (HAMERS \& BLANC, 2000); (MUYSKEN, 2011): o primeiro é o tag switches: envolve uma exclamação em outra língua, por exemplo, no Talian, a expressão 1 abaixo, é chamada também de "emblematic switching";

\section{"Porco Dio"s}

O segundo, chamado code-switching intrasentencial, refere-se à alternância entre as línguas que ocorre no meio da sentença, por exemplo no hunsriqueano,

(2) "Ich sin bei de vizinho gang para ver se ele empresta a plantadeira fo soja planze"9

Este tipo de Switching foi chamado em 1989, por Hamers \& Blanc (2000 p. 60), de CodeMixing, discordando, portanto, da opinião de Poplack. O terceiro tipo, denominado code-switching intersentencial, ocorre quando o falante inicia a sentença em uma língua e a conclui em outra, conforme o exemplo oriundo de uma variedade do Polonês:

(3) A tá, aquela, só que vai ter que pegar algum protetor, algum creme bo to muchy będzie pożerać... ${ }^{10}$

Por muito tempo, o Code-Switching foi visto como uma deficiência no domínio de ambas as línguas. Contudo hoje, e graças ao estudo de Poplack (1980), fica claro que o falante que realiza o Code-Switching possui um alto grau de domínio e conhecimento sobre ambas as línguas. Para Muysken (2011, p. 312),

8 Tradução: 'Deus Porco!'(tradução nossa)

9 Tradução: 'Eu fui no vizinho para pedir a plantadeira de soja emprestada'. (tradução nossa)

10 Tradução: 'A tá, aquela, só que vai ter que pegar algum protetor, algum creme porque as moscas vão devorar...' (KRUG, HORST, WEPIK, 2016). 
O Code-Switching pode ser visto como uma tentativa dos falantes para incluir toda a gama de sua competência linguística ao falar com os colegas bilíngues, para maximização de efeitos estilísticos, etc. (MUYSKEN, 2011, p. 312).

Um ponto a ser explanado é a definição de empréstimo, que não deve ser confundido com CodeSwitching, mas que causa certa dificuldade na hora da distinção, principalmente nos casos de contato direto entre línguas (TREFFERS-DALLER, 2005). Para facilitar nosso entendimento, de acordo Treffers-Daller (2005, p. 1472) o empréstimo “... é frequentemente visto como a integração (adaptação ou incorporação) de elementos vindos de uma língua dentro de outra língua", ou seja, a adaptação de uma palavra de outra língua na língua base (GROSJEAN, 1982). Outra forma de diferenciar os dois fenômenos seria o fato de que o Code-Switching é uma estratégia do falante bilíngue, enquanto o empréstimo não (HAMERS \& BLANC, 2000, p. 270).

Um fator que colabora para a ocorrência do empréstimo é a inexistência de um termo em uma língua para expressar novos conceitos, objetos e lugares, oriundos das novas experiências socioculturais e a necessidade de comunicação entre si, conforme Mesquita (2009, p. 44), em sua pesquisa sobre empréstimos linguísticos do português em Xerente Akwé.

Em suma, no presente artigo, Code-Switching ocorre quando o indivíduo possui domínio de ambas as variedades linguísticas, o que lhe dá condições de ir e vir de uma para a outra variedade, seja entre palavras ou frases complexas, sem que isso interfira na comunicação e na compreensão do assunto entre os interlocutores. Já considerando o empréstimo, o falante, geralmente, possui o domínio de apenas uma variedade linguística e utiliza apenas alguns termos provenientes de outra variedade linguística, como por exemplo os anglicismos na língua portuguesa brasileira playlist, voucher, check-in, check-out, cool, crush, sold out, track, start-up.
A partir das nossas leituras e constatações in loco com a língua indígena Kaingang na TIG, propomos a definição de Code-Switching, como sendo uma forma de utilizar o empréstimo, o qual não exige dos interlocutores um amplo domínio de ambas as línguas, embora no Code Switching o conhecimento de ambas as variedades seja imprescindível. Dessa forma, poder-se-ia adotar o termo playlist como empréstimo no caso do falante somente conhecê-lo isoladamente. Já no caso de Code-Switching, o falante utilizaria o termo playlist tanto na língua portuguesa quanto na língua inglesa de diferentes formas e adequando o uso estrategicamente, de acordo com seu interlocutor.

Durante o discurso de um falante, observamos a presença do Switching entre a língua Kaingang e a língua portuguesa. A seguinte parte do discurso selecionada e apresentada abaixo (I) deixa evidente a ocorrência do switching intrasentencial, onde observamos a presença de vocábulos da língua portuguesa numa sentença Kaingang; ainda registramos, a partir de (II), o switching intersentencial, quando o falante alterna entre sentenças em Kaingang e sentenças em português ou, neste caso, inicia o tópico em uma língua e em seguida passa para outra:

(I) “Kãg tỹ jag mré vãmén si han ge ṽ̃ viv áh... áh ag almoço tỹ demorar ke si han mũ kar ag tỹ ag mỹ ãg setor kãg ki... é jag passa ke sĩ ham mé, mỹr kenjé ag tỹ é... organização é mág tavi ta nĩ kenjé amã comunidade kagki, kar ãjog tỹ krãm nỹtĩ tag mré ajag mỹ passa kej mũ gé han, ãg tỹ pavilhão ti... tá há han jé ãjag tr̃ kar ãg ajuda

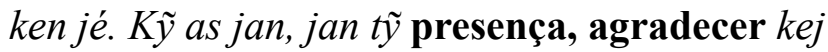
mũ ké. (II) Também quero agradecer a presença da diretora, da professora José, e demais os professor que se fazem presente no dia de hoje. Eu quero agradecer também a diretora, onde ela concedeu pra nós as cadeiras né, as mesa... que sempre ela, hãm, pronta a ajudar..."

11 Tradução: 'Então a gente conversa um pouco junto, o almoço deles demora um pouco, depois dentro do nosso setor, e vocês passam um pouco, pois eles, com nossa organização, é muito grande lá, dentro da nossa comunidade. Depois embaixo de onde vocês estão, passam vocês também o pavilhão, para mais tarde eles nos ajudar para depois do 
Nos casos de switching intrasentencial, buscamos referência no Dicionário Kaingang português, português - Kaingang (WIESEMANN, 2011), para melhor análise. Dessa maneira, observamos que as palavras almoço, setor, organização, comunidade e pavilhão não estão presentes entre os vocábulos do dicionário da língua Kaingang, o que nos leva a acreditar que essas palavras são empréstimos da língua portuguesa, ou seja, instâncias de Code-Switching.

Em contrapartida, nas palavras demorar, ajudar e passar encontramos vocábulos muito semelhantes, como demorar $=$ demorado que em Kaingang seria "KANĨM", e iguais como ajudar em Kaingang seria "KI RÃ KE" ou "MRÉ KI GE", e passar, que seria "VAG KE" ou "FĨN KE". De acordo com Wiesemann (2011, p. 08), "quanto mais o povo Kaingang se torna bilíngue, usando tanto o Português quanto “ $\square \mathrm{g}$ vî̀, mais palavras da língua portuguesa são usadas naturalmente no contexto de “ $\square \mathrm{g}$ vî" e pronunciadas como se fizessem parte dela". Já no switching intersentencial, no final do discurso, o falante alterna para o português, ou seja, inicia a frase em uma língua e a conclui em outra. Provavelmente, por se tratar de uma fala para várias pessoas presentes, incluindo indígenas e fóg, a alteração ocorreu, pois a mensagem emitida em português se dirigiu aos fóg. O mesmo parece ocorrer na frase III, a seguir:

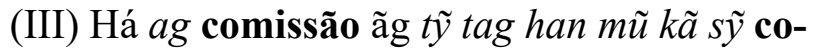
missão monta ké hãara ãg tỹ vãhã reunião, tag han ãn tỹ ãg pa'i ag mré, ag tỹ lida ke nỹty. ${ }^{12}$

Nesse caso, percebemos o switching intrasentencial, observando que, palavras como comissão e montar, não são encontradas no dicionário da língua Kaingang, sendo também consideradas

almoço agradecer a ajuda deles'. (Traduzido por falantes da língua Kaingang de Nonoai).

12 Tradução: 'Muito bom a comissão que estamos fazendo, muito bem montada. Depois a reunião feita com as lideranças onde estão tratando lá com eles'. (Traduzido por falantes da língua Kaingang de Nonoai). como empréstimos. Já no caso da palavra reunião, localizamos palavras semelhantes, como reunidos “V $\square$ NH PÃNPIR", e reunir-se "V $\square$ NH MÃN" ou "V $\square$ NH PÃNPIN". Assim, é provável que o falante tenha utilizado uma estratégia linguística na hora de se comunicar, preferindo usar o termo em português.

Sobre os empréstimos desses casos, que geram o Code-Switching, Haugen (1973), explica a existência de dois tipos de empréstimos: "os necessários" e "os desnecessários". Os "necessários” preenchem lacunas lexicais, enquanto que os "desnecessários" adotam o empréstimo de um item lexical de valor equivalente da língua, mas não o usa. Sendo assim, setor, pavilhão, comissão, almoço, organização, comunidade e montar, são exemplos de empréstimos necessários e demorar, ajudar, passar e reunião são empréstimos desnecessários.

Com base em Grosjean (1982), Mesquita (2009, p. 44) nos apresenta o seguinte exemplo de sua pesquisa, realizada com a língua indígena Xerente, para empréstimos necessários (a) e desnecessários (b):

(a) Tah«ââ za sadu vende

Tradução: 'Ele vai vender o colar.'

(b) Badikre buscá...t«ââkt«ââ

Tradução: 'Vai buscar a rede....agora!'

Poderíamos relacionar o uso de empréstimos “desnecessários” às atitudes dos falantes em relação à língua minoritária e de menor prestígio. Caso o falante apresente atitudes positivas, podemos crer que menos empréstimos desnecessários oriundos da língua majoritária e de maior prestígio serão usados, tendo como consequência um fortalecimento da língua de menor prestígio. Quando o contrário ocorre, mais chances existem de a língua minoritária ser substituída pela língua majoritária (MORENO FERNÁNDEZ, 1998; AGUILERA, 2008, p. 106). 
No caso dos grupos indígenas, para determinados falantes, a língua de prestígio pode ser o Kaingang, enquanto para outros pode ser a língua portuguesa. Isso varia, principalmente, de acordo com o contexto em que o falante está inserido/vive e do conhecimento que possui de si e dos outros. Assim, acredita-se que aquele indígena que ainda usa o Kaingang em suas relações diárias identifica-se com essa língua e apresenta atitudes positivas em relação a ela, trará menos empréstimos “desnecessários” para sua oralização.

O empréstimo pode funcionar como um gatilho para a ocorrência de Code-Switching e, no caso das línguas indígenas, isso funciona de uma forma peculiar, pois conforme ocorre a aculturação, novos e mais termos em uma outra língua surgem e passam a ser utilizados. Desta forma, como o falante indígena domina, na maioria das vezes, as duas variedades linguísticas em questão, ao utilizar um empréstimo da língua portuguesa, este (o gatilho) o leva a alternar para a língua portuguesa, ocasionando o Code-Switching.

Se pensarmos em questões de preservação e manutenção linguística, vemos a necessidade da atualização das línguas indígenas, que só ocorrerá mediante documentação e acesso facilitado à consulta dos novos termos. Aqui temos um amplo campo a ser pesquisado e implantado em prol da manutenção das línguas indígenas ${ }^{13}$.

Vejamos a frase IV:

\section{(IV) ...Seja ãg tỹ organiza $k e$ tug $k \tilde{y}$ as coisa} não vai pra frente né. Jog tỹ savĩn ke tuvãg mỹr hãraca jog rike tavĩ jã gé, eu to aqui como líder pra organiza junto com vocês né. ${ }^{14}$

\footnotetext{
13 Estratégias de atualização de língua, defendida pela professora Altaci Corrêa Rubim Kokama durante a live:" Línguas Indígenas: Revitalização e Retomada" realizada pela Associação Brasileira de Linguística - ABRALIN, em 17 de maio de 2020 e disponível pelo link: https://www.youtube. com/watch?v $=$ SKZ-auc7noQ. Acesso em: 03/07/2020.

14 Tradução: ‘...Seja, se nós não se organizar, as coisas não vão pra frente né. E se nós deixar só assim, então, igual...eu tô aqui como líder para organizar junto com vocês né’.
}

Em IV, na última parte a ser analisada, percebemos o switching intersentencial, pois o falante alterna entre sentenças indo e vindo entre as línguas. Nesse caso, entendemos que se trata de uma estratégia comunicativa utilizada pelo falante.

\section{Considerações Finais}

O Code-Switching, oriundo do contato entre línguas, permanece sob conflitos teóricos, principalmente quando a questão é a definição dos termos. Assim, após verificarmos a existência de contato entre Kaingang e fóg, também percebemos a existência dessa alternância entre línguas na fala dos indígenas.

Podemos ver e apontar, a partir dos nossos dados, que as principais formações de Code-Switching na variedade Kaingang ocorreram tanto dentro das próprias sentenças simples, definida como Switching intersentencial, como também entre as distintas sentenças, o Switching intrasentencial.

Com base nos exemplos apresentados, definimos o empréstimo como uma forma de utilizar vocábulos isolados de uma variedade linguística na outra, que não exige dos interlocutores um amplo domínio em ambas as línguas. As palavras surgem em forma de empréstimos "necessários", como por exemplo setor, pavilhão, comissão, almoço, organização, comunidade e montar, e vão sendo empregadas no Kaingang por não fazerem parte do vocabulário indígena, e vocábulos "desnecessários", como por exemplo, reunião, demorar, ajudar e passar, que são termos que existem na língua Kaingang, mas que estão sendo empregados em português. Contudo, na realidade bilíngue das comunidades indígenas, esse empréstimo pode agir como um gatilho para a alternância entre as variedades linguísticas que o falante domina, levando ao Code-Switching, seja ele intersentencial ou intrasentencial.

Com o presente artigo foi possível apresentar um pouco do contato existente entre a língua 
Kaingang e a língua portuguesa na TIG. Isso não quer dizer que o tema está finalizado, pelo contrário, há muito o que fazer ainda. As relações entre os falantes aqui apresentadas foram somente uma pequena amostra do grande potencial de pesquisas que há nessas comunidades, principalmente no que tange à manutenção e ou substituição da variedade indígena pela variedade portuguesa. Vale ressaltar também que, a partir da intensidade de uso de uma ou outra variedade linguística, podemos traçar o perfil sociocultural da comunidade Kaingang e medir o quão bilíngue ou monolíngue ela é. A partir dessa dimensão, também é possível verificar a velocidade de aculturação do povo Kaingang.

Por fim, é preciso incentivar a valorização e a preservação da variedade indígena e uma forma simples para isso é a devolução de estudos, a exemplo deste, para a própria comunidade frisando a importância de manterem viva a língua da comunidade Kaingang, pois sem ela, grande parte da sua cultura deles também será perdida.

\section{REFERÊNCIAS}

AGUILERA. Valdeci de Andrade. Crenças e Atitudes Linguísticas: o que Dizem os Falantes das Capitais Brasileiras. Revista Estudos Linguísticos, pg: 105-112, São Paulo, 2008.

APPEL, Rene; MUYSKEN, Pieter. Language Contact and Bilingualism. London: Edward Arnold, 1987.

D’ANGELIS, Wilmar R; VEIGA Juracilda. Habitação e Acampamentos Kaingang hoje e no passado. Cadernos do Ceon, no 18, p: 213-242. Chapecó, 2003.

FERRARI, Odemio. A Intersecção Religiosa entre o Povo Kaingang e o Pentecostalismo na Terra Indígena Guarita: Apropriações e Ressignificações. São Paulo, PUC/SP, 2012.

FRIZZO, Celina Eliane. Manutenção, Preservação e Perda do Bilinguismo: Português/Guarani/ Kaingang na Terra Indígena Guarita - RS. Dissertação de Mestrado. 2017

GASPARETO, Luciane M.O. Tenente Portela dos Índios: os Séculos da Presença Indígena nos Cinquenta Anos do Município de Tenente Portela. In: Memórias de Tenente Portela e Municípios Descendentes. (Orgs) LOPES, Fátima Marlise M. R; DANETTE, Vera Regina. Editora Unijuí, Ijuí, 2006, p. 17-36.

GROSJEAN, François. Life with two languages: an introduction to bilingualism. Harvard University Press, 1982.

GROSJEAN, François. Bilingual: life and reality. Harwaerd University Press, 2010.

HAMERS, F. Josiane; BLANC, Michel H. A. Bilinguality and Bilingualism. 2a edição, 2000.

IBGE-InstitutoBrasileirodeGeografiaeEstatística. Censo Demográfico 2010: Características Gerais dos Povos indígenas. Disponível em: <ftp://ftp. ibge.gov.br/Censos/Censo_Demografico_2010/ Caracteristicas_Gerais_dos_Indigenas/pdf/ tab_3_01.pdf>. Acesso em: 15/09/2014.

KAUFMANN, Göz. Atitudes na Sociolinguística. Aspectos Teóricos e Metodológicos. In: Os contatos Linguísticos no Brasil. Org: MELLO, Heliana; ALTENHOFEN, Cléo V; RASO. Tommaso. pg: 121-137, Belo Horizonte, 2011.

KRUG, Marcelo Jacó. Atlas das Línguas em Contato na Fronteira: Missões no Brasil e Missiones na Argentina (ALCF). Direitos reservados: FAPERGS/UFFS, 2013.

KRUG, Marcelo; HORST, Cristiane; WEPIK, Fernanda Fátima. Code Switshing na fala de polono-brasileiros em Áurea - RS. Domínios de Lingu@Gem, v. 10, p. 1404-1423, 2016.

MACKEY, Willian. The Description of Bilingualism. In: FISHMAN, J. Deadening in the Sociology of Language. $3^{\mathrm{a}}$ ed. The Hague, Monton, 1972. 
MESQUITA, Rodrigo. Empréstimos lingüísticos do português em Xerente Akwé. Dissertação, 2009.

MUYSKEN, Pieter. Code Switching. In: The Cambridge Handbook of Sociolinguistics. MESTHRIE, Rajend. Cambridge, 2011.

POPLACK, Shana (1980) "Sometimes I'll start a sentence in Spanish Y TERMINO EN ESPANOL: Toward a typology of codeswitching”, in: Linguistics 18, 581-618. 1980

ROMAINE, Suzan. Bilingualism. Oxford: Blacmvell. 2a ed, 1995.

ROMAINE, Suzanne. Contact and Language death. In HICKEY, Raymond (ed.). The Handbook of language contact. Oxford: Wiley-Blackwell, 2013. p. 320-339

SELLA, Aparecida Feola et al. Crenças e Atitudes Linguísticas em Foz do Iguaçu: perceptíveis por meio do léxico. In: SELLA, Aparecida Feola Sella; ROMAN, Elódia Constantino; CORBARI, Alcione Tereza. (Org.). X Celsul: Congregando Pesquisas. 2016, p. 145-166.

TRAFFERS-DALLER, Jeanine. Code Switching. In: Sociolinguistics. An International Handbook of the Science of Language and Society. AMMON, Ulrich [et al] $2^{\mathrm{a}}$ edição, 2005.

WIESEMANN, Ursula Gojtéj. Dicionário Kaingang - Portugês, Português - Kaingang. $2^{\mathrm{a}}$ edição, Curitiba, 2011.

WISNIEWSKI, Fernanda. A terra Indígena do Guarita -RS e o Seu Processo de Formação. 2011 Disponível em: < http:/ /www.snh2011.anpuh.org/ resources/anais/14/1300876916_ARQUIVO_ ArtigoAnpuh.pdf>. Acesso em: 01/07/2014.

Submissão: agosto de 2020.

Aceite: fevereiro de 2021. 